\title{
AN EXPLORATORY STUDY OF MENTAL ORGANIZATION IN SENILITY
}

\author{
BY \\ MARGARET DAVIẼS EYSENCK * \\ From the Laboratory for Clinical Research on Ageing $\dagger$ at the Tooting Bec Hospital
}

(Received 9TH February, 1945)

\section{Introduction}

THE fact that in the last few decades the proportion of the old and senile has been growing at an increasing rate and that this trend shows every likelihood of continuing has centred recent scientific interest on the psychological changes which take place in senility. As Dayton has shown (1940), Senile Dementia has now displaced Schizophrenia as the most common psychosis requiring hospital treatment, and many social problems are raised by the increasing average age of the population.

Studies have been made of the ability of old people, shown by tests of intelligence, memory, motor co-ordination, imagination, and other functions. The work of Wechsler (1942), Miles (1933), Thorndike (1928), Sorenson (1933), Ruch (1923) and others has left little doubt that mental ability decreases with increasing age once adulthood has been reached. It has also been shown that this decrease takes place at different rates for different tests, and a ratio of the relatively slowly decreasing Vocabulary Test to the relatively quickly decreasing abstract type of intelligence test has been made into an index of senile deterioration (Babcock, 1941; Gilbert, 1935).

While these facts may be regarded as established, further points of interest remain to be investigated. It appears possible that, in addition to the quantitative differences observed between the abilities of the old and the young, qualitative differences also might be observed. Qualitative differences and changes which Piaget considers to contribute to the growth of intelligence may also become evident in its decline. An investigation into this problem has been reported elsewhere (Eysenck, 1945).

Another problem will be dealt with in the present paper. None of the studies so far mentioned deal with the organization of the various abilities involved in the tests used; yet it seems reasonable to suppose that differences in organization should become apparent with advancing age. For instance, it has been reported that much higher intercorre-

* Research-psychologist at the Laboratory for Clinical Research on Ageing.

+ The Laboratory and the research on ageing were financed from the grants to the Club for Research on Ageing by Lord Nuffield and the Nuffield Foundation, to whom the Club and the author express their gratitude. They thank also the London County Council for all the facilities given at the Tooting Bec Hospital for the work. lations than are found for adults are usually observed for children. On the other hand, group factors often assume increased importance in the older subjects (Cattell, 1943). These facts make it necessary to extend the factorial study of mental abilities to senile groups in an attempt to throw some light on the organization of mental functions in old age.

\section{Method}

(a) Population.-The population used in this experiment consisted of well over 100 male patients with Senile Dementia at the Tooting Bec Hospital. This number was reduced during the course of the experiment through death, discharge from the hospital, etc., to below 100 . Approximately 10 per cent. were illiterate. These various factors reduced the number of patients included in the main experiment to 75 . Twenty of these had been labourers, handymen, carmen, and unskilled factory workers; 20 had been highly skilled workers (compositors, instrument makers, engravers, etc.), had been in business for themselves or had managed shops for others; the remaining 35 were either unclassifiable or had been employed in jobs roughly intermediate between the other two groups as regards the skill required in their previous profession. The average age was $73 \cdot 4 \pm 6 \cdot 5$.

(b) Administration.-Altogether 20 tests were given, which are described in Section $(c)$. The tests were given individually in two sittings separated by about six weeks. Testing time was 59 minutes on the average for the first sitting and 51 minutes on the average for the second sitting. Wide individual variations were, of course, encountered. The whole battery of tests was repeated after four months. The patients were tested at the same time of day as before. On the repetition the average time for the first sitting was 48 minutes (with two tests omitted); the second sitting 44 minutes. Thus each of the patients was tested individually for an average of approximately three and a half hours.

Eighty-four patients altogether were tested twice on all the tests, except for the fact that 9 patients were illiterate and were incapable of doing two of the tests requiring writing. Test-retest reliabilities were calculated on the 84 for all the tests except the two writing tests; correlations were calculated only for the 75 patients who had done all the tests including the writing tests.

(c) Tests.

Psychological Test Battery (given on first sitting):

(1) Orientation.-The first test was presented as a necessary formality. The patient was asked his full name, his age, date of birth, the current day's date, the approximate hour of the day, and the letter and number of the ward he was in. The total possible score on this test is 5 points.

(2) Progressive Matrices. - The individual board form 
of Raven's Progressive Matrices was given (1940). The board form consists of only Sets "A " and "B " of the total Matrix Test. The total possible score on this test is 24 points.

(3) Digits Forward.-This test was given in the usual way, starting with two digits and continuing till three successive attempts at any particular number of digits had failed.

(4) Digits Backward.-This was given in exactly the same way as Test (3). In both tests the highest number of digits correctly repeated or reversed constituted the score.

(5) Immediate Memory.- - The story " Three Houses on Fire" (Burt, 1933) was read to the patient after he had been warned that he would be asked to tell as much as he could remember of it. His free memory was supplemented by questions, as the senile patients' spontaneous response did not do justice to their memory. This story aroused much emotional reaction, the incident described becoming identified with the London blitz, and another, more neutral, story was substituted in the second testing. Spontaneous memory and answers to questions counted equally towards total score. Maximum score on both stories was 20 points.

(6) Fluency.- The patient was asked to name as many kinds of (a) animals, $(b)$ birds, and (c) flowers as he could in one minute each. Scores on these three subtests were combined to give the total number of objects named during three minutes. Timing started when the patient pronounced the first name in each series.

(7) Days of the Week.-The patient was asked to say the days of the week as quickly as he could, the time taken being his score.

(8) Days of the Week Backward.-The patient was asked to say the days of the week backward as quickly as he could, the time taken being his score.

(9) Months of the Year.-The patient was asked to say the months of the year as quickly as he could, the time taken being his score.

(10) Months of the Year Backward.-The patient was asked to say the months of the year backward as quickly as he could, the time taken being his score.

(11) Delayed Recall. - At the end of Test (5) the patient was told that he would be required to retell the story later on. He was now asked to do so, scoring being exactly as in Test (5).

(12) Vocabulary.-The Mill Hill Vocabulary Test was used, the patient being required to supply definitions for a series of 44 words increasing in difficulty. The number of correct definitions constituted his score.

(13) Writing Name.-The patient was asked to sign his name with a soft pencil on unlined paper. The time taken was recorded and scored as the rate per 10 letters.

(14) Writing from Dictation.-The patient was asked how long he had been in the hospital and then told to write "I have been here ... years (or months)." This was also scored as the rate per 10 letters.

(15) Incidental Memory.-The patient was asked to recall as many of the different problems he had done as possible.

The following two tests were used on the first testing but were then dropped from the battery.

(i) Colours.-The four colours given by Burt (1933) were presented to the patient and he was asked to name them. He was also asked to say which he liked best, second best, and so on.

(ii) Porteus Mazes.-This test was rejected because it was too difficult for many of the subjects, and because vision plays too large a part in it.

Motor Test Battery (given on second sitting):

(16) Strength of Grip: Dynamometer.-This test was given to the patient with his elbow resting on the table and the other hand on his knees. Two tests were done for each hand in alternation. The average of these four scores, in kilograms, constitutes the score of the patient.

(17) Speed of Tapping.- The patient stood with his left hand gripping the back of a chair and was asked to tap with his other hand as quickly as he could from one metal plate to another for 30 seconds. After 30 seconds' rest the test was repeated. The number of double taps on both trials together constitutes his score.

(18) Arm Ergograph.-The patient's arm above the elbow was strapped to an arm rest while his hand lay on a metal disc which he was required to press against the resistance of a spring. The extent of each stroke was recorded on a kymograph. The patient was told to keep time with a metronome and continued the test for two minutes. A two minutes' rest was interpolated, and another two minutes' trial performed. The score used was the average length of stroke expressed in terms of eighths of an inch.

(19) Ink Blot.-To allow the patient to recover from the exertion of the previous test a non-motor test was introduced here. He was shown a coloured ink blot and asked to pick out as many different things in it as he could. He was stopped after $2 \frac{1}{2}$ minutes. The number of items given constituted his score. (This test was not included in the factor analysis because of its low test-retest reliability, $r=0.46$, and because of its extremely low correlations with the other tests.)

(20) Steadiness. - The patient was required to hold a stylus inside a hole in a metal plate without touching the side. Holes of different diameter were used (the test is illustrated in Whipple (1924, p. 157) ). Each trial continued for 15 seconds. The score was determined by a combined measure of size of hole and number of touches, the higher the score the better the performance on this test.

The following two tests were used on the first testing but were then dropped from the battery.

(a) V-groove.-In this test the patient was required to trace a path between two gradually narrowing lines. This test was dropped as a measure of steadiness in favour of Test (20) after the first testing had been completed. In order to obtain a reliability coefficient for Test (20) it was given twice on the occasion of the second testing, once at the beginning, and again at the end of the sitting.

(b) Persistence.-The patient was asked to hold a weight in his outstretched hand for as long as he could, the time he held up the weight constituting his score. The test was repeated after two minutes' rest, and proved so unreliable that no further use was made of the data.

\section{Results}

In Table I are given the average performances on the first and second testing, the S.D.'s of the scores, the average improvement of the second testing expressed as a percentage of the score on the first testing, and the reliability coefficients for the various tests. The reliabilities of the combined (averaged) scores on the two testings, as estimated by the Spearman-Brown Prophecy Formula are also given. Except where otherwise stated these combined scores were used in all the calculations reported in this paper.

Perhaps the first point that will be noticed in the table is the fact that the S.D.'s are relatively large. This would naturally be expected from the test scores of subjects so divergent in cultural background, education, professional status, and deterioration.

Of the 18 tests where average improvement could be calculated, 5 showed deterioration. Of the 4 motor tests included 3 show a decrease on the second testing, probably indicating that the passage of time, even a few months, causes some deterioration in physical strength in subjects of so advanced an age. As will be seen later, the motor test scores correlate more strongly with age than do the rest. 
TABLE I

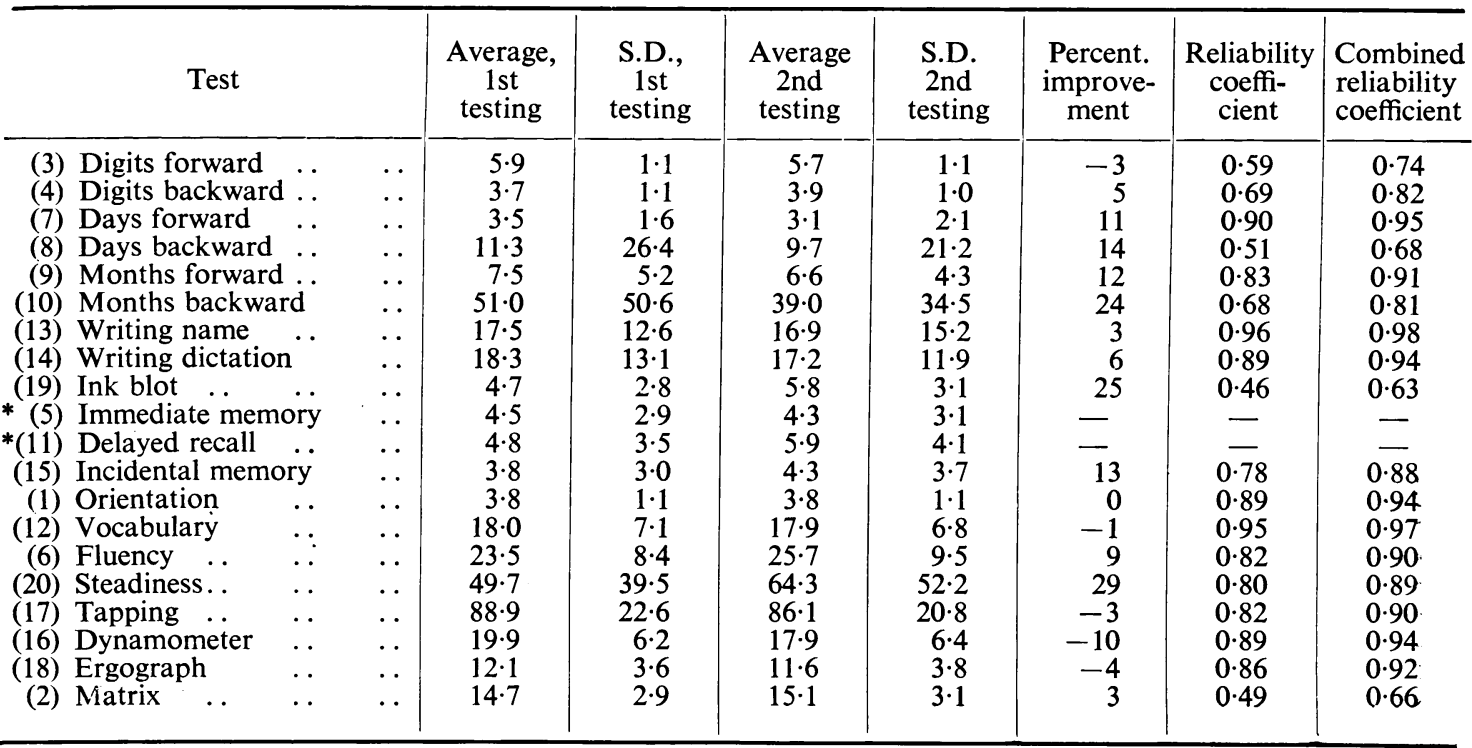

* In the case of these two tests the scores on the second testing only were used. As different stories were used on the first and second testing the reliability coefficient would not be comparable to the others.

The fourth motor test, steadiness, however, shows the largest amount of improvement. As has been explained, this particular test was substituted for another after the first testing, and was given to the subjects at the beginning and at the end of the second testing. It is natural, therefore, that the practice effect should come out most strongly: in every other case there was a time interval of three or four months between the first and second testing, whereas not more than 25 minutes elapsed between the two testings in the case of the steadiness test. The general tendency for the scores of the other tests to improve on the second testing is undoubtedly due chiefly to the practice effect and in a few cases to the better rapport secured.

On the whole the reliability coefficients are rather higher than might have been expected with these subjects. When the combined scores of the first and second testing are used, a fair degree of reliability is achieved.

In Table II are shown the product-moment correlations run between 20 variables for 75 sub jects. Of the 190 correlations only 9 are negative, none significantly so. With the level of significance according to Fisher's method being $0.22(p=0.05)$, it is seen that 101 of the correlations reach or exceed it. At the $p=0.01$ level of significant, $r=0.29$, and 69 of the correlations reach or exceed it.

The correlations seem to fall into three fairly well defined groups, and Burt's group factor method (1940) was accordingly used to factor analyse the table. The great majority of the tests fit in well with these group factors; four tests, whose attribution is doubtful, have the group factor saturation shown in brackets, viz. vocabulary, fluency, matrix, and age. The factor saturations appear in Table III.

The interpretation of the three group factors presents little difficulty. The majority of the tests making up Group Factor I are tests involving speed. The inclusion of the digits tests, however, makes it difficult to consider this factor as one purely of speed. It is of interest to note that days forward,

TABLE II

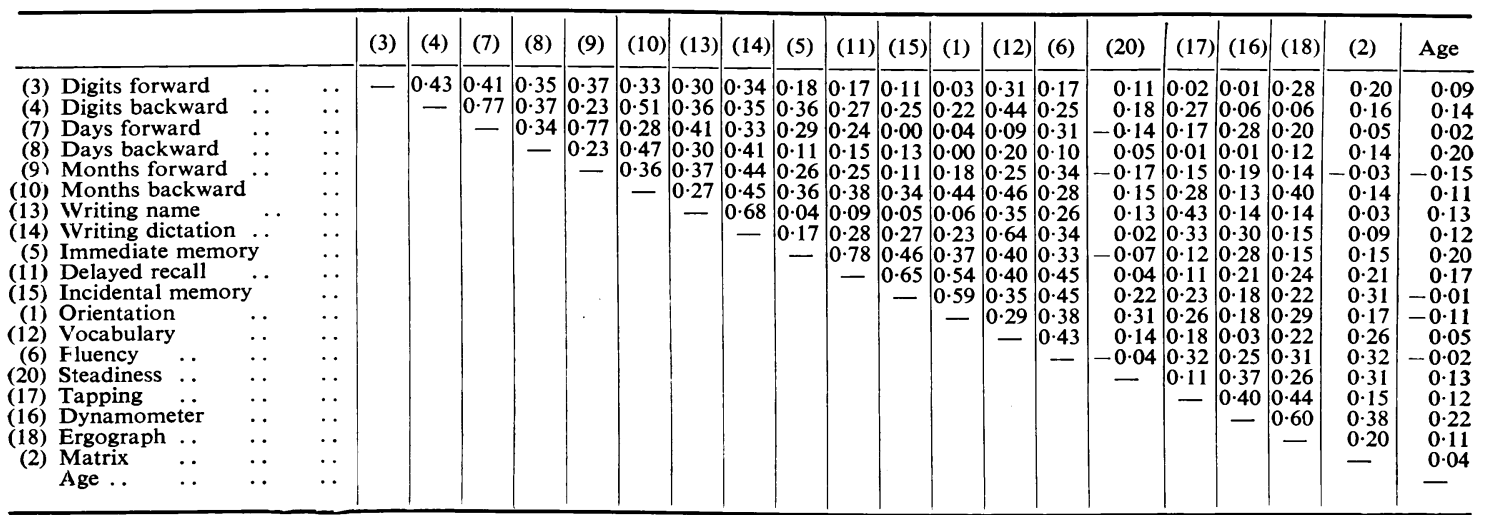


months forward, and writing name have in every case higher saturations than their companion test, where something a little more out of the ordinary is required, namely, days backward, months backward, and writing dictation. In the light of these six tests it would appear feasible to say that this factor goes some way towards measuring the natural speed of the subject.

TABLE III

\begin{tabular}{|c|c|c|c|c|c|}
\hline & Test & $\begin{array}{l}\text { General } \\
\text { Factor }\end{array}$ & $\begin{array}{l}\text { Group } \\
\text { Factor } \\
\text { I }\end{array}$ & $\begin{array}{l}\text { Group } \\
\text { Factor } \\
\text { II }\end{array}$ & $\begin{array}{l}\text { Group } \\
\text { Factor } \\
\text { III }\end{array}$ \\
\hline \multirow{2}{*}{\multicolumn{2}{|c|}{$\begin{array}{c}\text { (3) Digits for- } \\
\text { ward } \\
\text { (4) Digits back- } \\
\text { ward }\end{array}$}} & 0.33 & 0.45 & - & - \\
\hline & & 0.52 & 0.45 & - & - \\
\hline \multirow{2}{*}{\multicolumn{2}{|c|}{$\begin{array}{l}\text { (7) Days for- } \\
\text { ward } \\
\text { (8) Days back- } \\
\text { ward }\end{array}$}} & $0 \cdot 30$ & $0 \cdot 77$ & 一 & 一 \\
\hline & & $0 \cdot 24$ & 0.51 & - & - \\
\hline \multicolumn{2}{|c|}{$\begin{array}{l}\text { (9) Months for- } \\
\text { ward }\end{array}$} & 0.30 & 0.57 & 一 & 一 \\
\hline \multirow{2}{*}{$\begin{array}{l}\text { (10) } \\
\text { (13) }\end{array}$} & $\begin{array}{l}\text { Months } \\
\text { backward }\end{array}$ & 0.67 & 0.25 & 一 & - \\
\hline & $\begin{array}{c}\text { Writing } \\
\text { name }\end{array}$ & 0.36 & 0.47 & - & 一 \\
\hline \multirow{2}{*}{$\begin{array}{r}(14) \\
(5)\end{array}$} & $\begin{array}{l}\text { Writing dic- } \\
\text { tation } \ldots\end{array}$ & $0 \cdot 57$ & $0 \cdot 41$ & - & - \\
\hline & Immediate & 0.51 & - & 0.45 & - \\
\hline \multirow{2}{*}{$\begin{array}{l}\text { (11) } \\
\text { (15) }\end{array}$} & $\begin{array}{l}\text { Delayed re- } \\
\text { call } \quad \ldots\end{array}$ & 0.55 & - & 0.76 & - \\
\hline & $\begin{array}{l}\text { Incidental } \\
\text { memory. . }\end{array}$ & 0.47 & - & 0.66 & - \\
\hline \multirow{6}{*}{$\begin{array}{r}(1) \\
(12) \\
(6) \\
(20) \\
(17) \\
(16)\end{array}$} & Orientation & 0.45 & - & 0.43 & - \\
\hline & Vocabulary & 0.71 & 一 & $(0 \cdot 01)$ & - \\
\hline & Fluency & 0.62 & - & $(0 \cdot 17)$ & \\
\hline & Steadiness & $0 \cdot 14$ & - & - & $\begin{array}{l}0.46 \\
0.27\end{array}$ \\
\hline & Tapping .. & 0.45 & - & 一 & \\
\hline & meter & 0.35 & - & - & 0.88 \\
\hline \multirow{3}{*}{$\begin{array}{r}(18) \\
(2)\end{array}$} & Ergograph & $0 \cdot 45$ & 一 & - & 0.47 \\
\hline & Matrix & $0 \cdot 34$ & - & - & $(0 \cdot 25)$ \\
\hline & Age & $0 \cdot 15$ & - & - & $(0 \cdot 16)$ \\
\hline \multicolumn{2}{|c|}{ Variance } & $0 \cdot 20$ & $0 \cdot 10$ & 0.07 & 0.06 \\
\hline
\end{tabular}

Group Factor II is mainly concerned with tests of memory; even the bracketed tests (vocabulary and fluency) are at least in part a matter of (long term) memory.

Group Factor III is made up of tests of physical strength and ability. Age, while its membership in this group factor is somewhat doubtful, shows a tendency to be more strongly related to physical strength than to the other groups of more strictly psychological tests. The one exception to this is the matrix, the aptness of whose inclusion here is also in doubt. From this analysis it would appear that this test is rather more in agreement with the motor powers than with the mental powers in the case of these aged subjects. It must be borne in mind, however, that any definite conclusions about the relation between age and physical and mental powers could not be looked for from a population whose ages were so closely grouped together, and whose mental and physical deterioration were from observation comparatively unrelated to age. An investigation with a wider range of middle-aged and old people might show more clearly the exact relation between advancing age and deterioration in mental and physical abilities.

The general factor presents certain difficulties in interpretation. The factor saturations of such tests as have been used in previous factorial studies of children or adults below the age of this test group present a distinctly different pattern from that found here. If the present general factor were identical with that found in the usual type of analysis we should expect the matrix test to show a higher saturation than 0.34 , and we should expect the motor tests to show little or no appreciable saturation with this factor. It seems reasonable to conclude that the unequal deterioration of various kinds of ability in old age leads to a different pattern of organization from that found in normal adults. In understanding the changes which take place in the mental life of the aged knowledge of the organization of their abilities as well as of the comparative strength of these abilities is of obvious importance.

Cattell (1943) draws a distinction between two kinds of adult mental capacity which he calls " fluid" and " crystallized."

" Fluid ability has the character of a purely general ability to discriminate and perceive relations between any fundaments, new or old. It increases until adolescence and then slowly declines. ... Crystallized ability consists of discriminatory habits long established in a particular field, originally through the operation of fluid ability, but no longer requiring insightful perception for their successful operation. Intelligence tests test at all ages the combined resultants of fluid and crystallized ability, but in childhood the first is predominant whereas in adult life, owing to the recession of fluid ability, the peaks of performance are determined more by the crystallized abilities."

If this hypothesis is true, we should expect tests of fluid ability, such as the matrix, to have very high factor saturations in a study of adolescents and young people generally but to give low factor saturations in extreme old age; while, conversely, crystallized abilities would give comparatively high factor saturations in old age. This is precisely what we do find in this analysis, and we may, therefore, consider that this analysis gives a certain measure of support to the theory set forth by Cattell.

This opinion is not in accord with Cattell's own view about the consequences of his theory. He writes:

" . . . if the crystallized abilities are, as it were, a dead coral formation revealing by its outlines the limits of growth of the original living tissue, these crystallized abilities will show approximately the same intercorrelations as the original fluid abilities."

He goes on to say that "we should expect the intercorrelations to approximate the childhood values but to be systematically lower," and gives several reasons to justify his argument. 
This argument is possibly over-simplified, and does not do justice to the facts. What we are dealing with are abilities, both crystallized and fluid, which have deteriorated at different rates; they would show approximately the same correlations as the childhood values, on a rather lower plane, only if the rate of deterioration could be shown to be perfectly correlated with the extent of the original abilities. But there is no evidence in favour of this assumption; what evidence there is argues rather for a comparatively slight correlation, or none at all. Thus for a young person, a measure of fluid ability like the matrix would intercorrelate with his other abilities very highly, and have a high factor-saturation for " $\mathrm{g}$ "; for a senile person, there is no reason to suppose that what remains of his fluid ability, as measured by the matrix, should intercorrelate very highly with his crystallized ability, as measured by the vocabulary test, for instance. Proof of this assertion is given below. The same argument holds when we are dealing with tests involving both fluid and crystallized ability in varying proportions.

Further support for this view comes from a consideration of the scores of seniles on some of the tests used and a comparison of these scores with those of normal adult groups. The best representative of " crystallized" ability is probably the vocabulary test. On this test the seniles' average score is well above the 14-year-old level for normal subjects. The range between + and -1 S.D. about the mean extends from the average verbal ability of normal adults to that of 9 to 10 -year-old children. Compared with normal adults their average score is around the 25 th percentile.

The most representative test of "fluid" ability perhaps is the matrix test, on which the average performance of the senile group is almost identical with that of 8-year-old children. In terms of the normal population the seniles would come between the 3rd and 4th percentiles.

A comparison between the results of these two tests shows clearly the differential deterioration of the abilities concerned. It is impossible, of course, to tell from our data whether, and if so to what extent, the "crystallized" ability has decreased; in other words, it is not claimed that a measure of absolute deterioration can be given from the data.

For normal adults the progressive matrices test and the Mill Hill vocabulary test show a correlation in the neighbourhood of 0.6 . The correlation found between the scores on these two tests for the senile patients is only $\mathbf{0} \cdot 26$. Even when this correlation is corrected for attenuation by the use of Hull's formula $(1928$, p. 243) it rises to only 0.33 , and is thus very significantly lower than even the uncorrected correlation obtaining for normal adults. This would seem to indicate that not only do the abilities measured by these two tests deteriorate at unequal rates, but also that the rate at which the abstract type of ability measured by the matrix test deteriorates is not highly correlated with the original amount of that ability possessed by the subjects.
On the whole, the conclusions drawn from the comparison of the results of the matrix and vocabulary tests for the seniles agree with those drawn by Cleveland and Dysinger (1944).

“The majority of institutionalized senile patients are unable to sort objects on the basis of conceptual or abstract principles, but are limited to concrete bases. . . . (They) were able to respond to many of the verbal items in the Wechsler-Bellevue Scale on an apparently abstract verbal level, but were unable to sort objects on an abstract or conceptual basis. This appears to be due to the fact that a patient may use what seems to be an abstract verbal concept with much more restricted meaning."

On digits forward the seniles' average score of 5.9 is roughly equal to the norm for 8-year-olds. On the original Binet immediate memory test their average of 4.7 appears to be slightly higher than the 8 -year-old level. Owing to the different method employed it is not possible to equate the results with any great exactitude.

Wechsler's paper on "Intellectual Changes with Age" (1941) includes an interesting graph, based on Galton's data, showing the mean grip in pounds (right hand) for males from age 5 to 80 . The average dynamometer score for the seniles (right hand) transformed into pounds is about 44 , which corresponds approximately to that found for the 15 -year-olds, and is considerably lower than Galton found for 80-year-olds. The difference of time, nearly 70 years, between Galton's work and this investigation, is yet another factor making a direct comparison difficult; the type of dynamometer used, the technique, as well as the likelihood that this particular sample of seniles is not truly representative (being composed of a large number of men accustomed to hard physical labour, who probably lack their usual exercise and diet in hospital), all contribute to the uncertainty of any conclusions that might be drawn. It appears safe to say that there is some deterioration demonstrated in this test of dynamometer grip, but it seems to be somewhat less pronounced than the deterioration observed in the mental tests.

In an effort to make further deductions from the data collected, the 75 subjects were divided into three groups: 20 whose previous profession had been definitely superior to the average of the whole group; 20 whose previous profession had been definitely inferior to the average; and the remaining 35 whose profession was either uncertain or about the average level for the whole group. In Table IV average scores for the top and bottom groups are shown, the difference between their scores, the S.D. for the whole group of 75 , and the difference expressed in terms of these S.Ds. The figures in the last column, it should be noted, are not critical ratios; nor are they in any sense estimates of the statistical significance of the differences; they are intended rather to make possible a comparison of the differences observed between the two groups in the various tests. 
TABLE IV

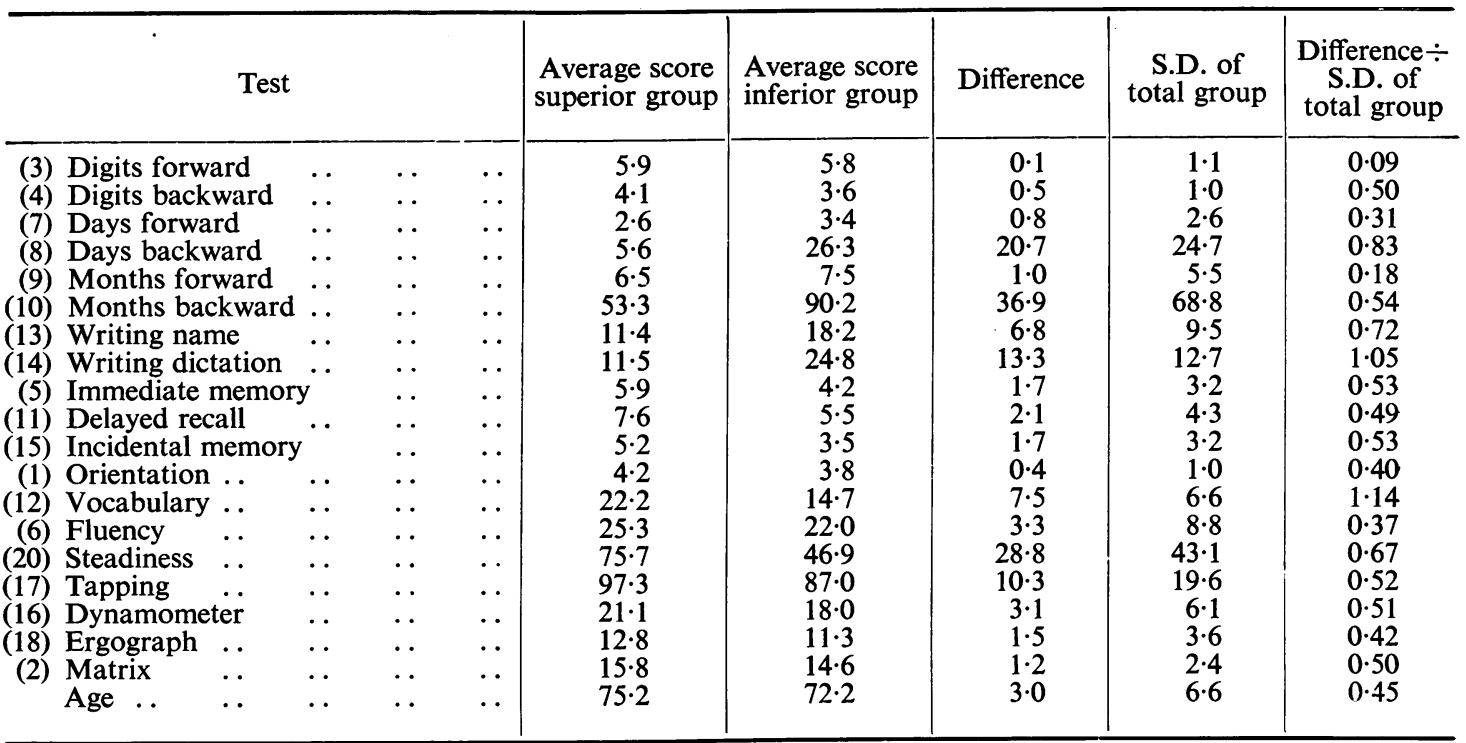

The first point of interest is that on every single test the superior group scores more highly than the inferior. It is perhaps surprising that on the tests of physical strength also this superiority shows itself. As we have seen, there is a slight tendency for age to correlate with these motor tests (i.e. the younger subjects tend to do rather better on the whole), and what little difference there is in age between the two groups favours the inferior. Possibly part of the explanation is the better nutrition the superior group have enjoyed before hospital, and perhaps in it owing to their larger supply of spending money for extras at the patients' canteen.

The largest differences, as shown by the figures in the last column of the table, are in the vocabulary and the writing from dictation tests. That is probably what one might have anticipated from the way in which the two groups were selected. It is interesting to note that the digits backward, days backward, and months backward tests in each case show a larger difference between the two groups than do the digits forward, days forward, and months forward tests. The matrix test shows comparatively little discrimination between the two groups, less than the purely physical tests on the average.

In Table $\mathrm{V}$ are shown the varying distributions of the vocabulary scores for the two groups, as compared with a normal adult group, and with the total group of 75 seniles.

This shows clearly the difference in the results of the vocabulary test of the two groups. Only 10 per cent. of the inferior group reach the "average," whereas nearly half the superior group are " average" or better. It will be noted that even the superior group have 55 per cent. " definitely below average." Judging from the occupations followed it would appear improbable that such a high proportion of them in their prime were unable to achieve at least average verbal rating. However, it is well known that one of the chief difficulties of all vocabulary tests is that the words employed in common speech change from generation to generation, and even granting the possibility that the vocabulary grows until about the age of 40 , a whole generation has intervened since the vocabulary of these subjects was laid down.

TABLe V

\begin{tabular}{|c|c|c|c|c|}
\hline \multirow{2}{*}{ Verbal ability } & \multicolumn{4}{|c|}{ Percentage of each group } \\
\hline & $\begin{array}{c}\text { Normal } \\
\text { adults }\end{array}$ & $\begin{array}{l}\text { Whole } \\
\text { group } \\
\text { seniles }\end{array}$ & $\begin{array}{c}\text { Superior } \\
\text { seniles }\end{array}$ & $\begin{array}{l}\text { Inferior } \\
\text { seniles }\end{array}$ \\
\hline $\begin{array}{ll}\text { Superior } & . . \\
\text { Above average.. } \\
\text { Average } & . \\
\text { Below average } & . \\
\text { Defective } & .\end{array}$ & $\begin{array}{r}5 \\
20 \\
50 \\
20 \\
5\end{array}$ & $\begin{array}{r}0 \\
8 \\
27 \\
47 \\
18\end{array}$ & $\begin{array}{r}0 \\
20 \\
25 \\
55 \\
0\end{array}$ & $\begin{array}{r}0 \\
0 \\
10 \\
55 \\
35\end{array}$ \\
\hline
\end{tabular}

These results cover the tests included in the final battery. It may be of interest to mention briefly some results of the colour test which was originally included in the psychological test battery but which was later removed.

In all, 110 subjects did the test with sufficient understanding for their results to be used. Of this number 19 saw one or more of the colours, red, green, blue, and yellow, imperfectly. In 10 cases green was seen as blue of some sort, and upon questioning they asserted that there was no green there at all. Red was seen as mauve by two subjects and another two saw it as brownish. These findings suggest that perhaps colour vision declines in old age, a conclusion in line with the results of Smith (1943). 
In addition to naming the colours, the subjects were asked to rank them in order of preference. The 19 who were unable to see all four colours correctly were omitted in this calculation, leaving 91 ranking orders. Blue was liked best, getting an average score of 1.55 , while yellow was liked least, with an average score of 3.37. Red and green were almost equally popular, with an average score of 2.71 and 2.37 respectively. In H. J. Eysenck's work on colour preferences (1941) he found blue the favourite and yellow the most disliked of these particular four colours; but the positions of red and green were reversed. As the shades used in these researches were not identical, however, too much importance should not be attributed to this reversal.

The average intercorrelation of the rankings in the group of seniles was 0.32 , which is almost identical with that found by $\mathbf{H}$. J. Eysenck in his study $(r=0 \cdot 28)$.

\section{Summary and Conclusions}

Twenty psychological tests were given individually to 84 senile dementia patients and repeated after four months, total testing time per patient being approximately three-and-a-half hours. The average age of the patients was $73.4 \pm 6.5$ years. Testretest reliabilities were established for the tests used, and intercorrelations run between the tests. A factorial analysis was carried out on these intercorrelations, in an attempt to throw some light on the type of mental organization to be found in senility. Comparisons were made between the scores of the patients on various tests and the scores of normal adults and children on these tests. A comparison was also made between the scores on the tests of a "superior" and an "inferior" group of seniles, as determined by the level of the skill required in the work they had been doing in the course of their lives.

With few exceptions, the reliabilities found for the tests were remarkably high, thus demonstrating that it is quite feasible to apply psychological tests of the type used even to senile dementia patients. A slight improvement was found for most of the tests from first to second testing, which was probably due to practice effects and " test sophistication."

The factor analysis resulted in a factor-pattern which accounted for 43 per cent. of the variance, $a$. general factor contributing 20 per cent. to the variance, and three group-factors, identified as being concerned mainly with speed, memory, and physical strength, contributing 10,7 , and 6 per cent. respectively.

The general factor presented a picture of the mental organization of the patients which differed greatly from that found in normal adults. An attempt was made to account for this difference in terms of the theory of "fluid" and " crystallized" ability.

The level of the senile patients on the progressive matrices test of abstract non-verbal ability approximated that of 8-year-old children; similarly, their performance on the digits repetition test was similar to that of 8-year-old children. On the vocabulary test, however, the seniles scored well above the 14-year-old level. The correlation between matrix and vocabulary for the senile patients was shown to be very significantly lower than the same correlation for normal adults. These facts were also brought into relation with the theory of "fluid" and "crystallized" ability.

The comparison of the superior and the inferior senile patients showed the superior group consistently scoring at a higher level than the inferior group, even on tests of physical strength. The degree of superiority, however, varied within wide limits.

The results allow the following conclusions :

(a) Mental ability in the seniles tested has considerably deteriorated.

(b) This deterioration affects most strongly tests involving abstract reasoning ability (" fluid " ability).

(c) This deterioration affects least tests involving a mere reactivation of past experiences and knowledge ("crystallized" ability).

(d) Due to the differential deterioration in the abilities of senile patients, the organization of these abilities, as compared with normal adults, becomes profoundly altered.

The author is indebted to Dr. P. Turnbull, Medical Superintendent of the Tooting Bec Hospital, for the facilities given during the research work; and to Drs. Aubrey Lewis, Wm. Stephenson and P. E. Vernon for their many helpful suggestions. The author also wants to thank Mr. H. Halstead and Mr. J. C. Raven for supplying her with certain unpublished data.

\section{REFERENCES}

Babcock, H. (1941). Time and the Mind. Cambridge, Mass., Sci.-Art Publishers.

Burt, C. (1933). Handbook of Tests. London, King and Staples.

(1940). The Factors of the Mind. London, Univ. Lond. Press.

Cattell, R. B. (1943). Psychol. Bull., 40, 153.

Cleveland, S. E., and Dysinger, D. W. (1944). J. abnor. Soc. Psychol., 39, 368.

Dayton, N. A. (1940). New Facts on Mental Disorders. Springfield, Ill. C. C. Thomas.

Eysenck, H. J. (1941). Amer. J. Psychol., 54, 385.

Eysenck, M. D. (1945). (To be published).

Gilbert, J. G. (1935). Arch. Psychol. No. 188. "Mental Efficiency in Senescence."
Hull, C. L. (1928). Aptitude Testing. Yonkers, World Book Co.

Miles, W. R. (1933). Psychol. Rev., 40, 99.

Reven, J. C. (1940). Mental Health, 1, 10.

Ruch, F. L. (1933). Psychol. Bull., 30, 387.

Smith, H. C. (1943). J. gen. Psychol., 29, 191.

Sorenson, H., (1933). J.appl. Psychol., 17, 729.

Thorndike, E. L., Bregman, E. O., Tilton, J. W., and Woodyard, E. (1928). Adult Learning. New York, Macmillan.

Wechsler, D. (1941). Intellectual Changes with Age. United States Public Health Service, Suppl. No. 168. (1942). Measurement of Adult Intelligence. New York, Williams and Wilkins Co. (2nd Edit.).

Whipple, G. M. (1924). Manual of Mental and Physical Tests. Baltimore, Warwick and York. 